\title{
The Study on Method Choice in the Supply of
}

\section{Rural Public Goods}

\author{
Yinhu Wang \\ Trade College, Shihezi University, Shihezi 832000, Xinjiang, China \\ E-mail: shaokaodyu@sina.com
}

Lin Yu (Corresponding author)

Professor, Trade College, Shihezi University, Shihezi 832000, Xinjiang, China

E-mail: shaokaodyu@sina.com

\begin{abstract}
In the new rural development framework, the supply of public goods in rural areas is a huge systematic project, which needs aspects of reform and adjustment. At present, the supply of public goods in rural areas faces many difficulties. It is particularly important to establish an effective public decision-making allocation mechanism, improve the irrational supply structure and adjust the supply of the induced pattern of supply and compulsory. This paper, the entropy point of view, based on minimum entropy principle, through self-organization functions and the external environment of supply system, according to positive entropy flow or negative entropy flow supply system, resulting in both the mandatory supply system and the induced supply system can not effectively prevent the system entropy increase. The most effective way is to make the mandatory supply system and the induced supply system fully integrated, complementary advantages, so as to gradually evaluate the supply efficiency of rural public goods.
\end{abstract}

Keywords: Rural public goods, Entropy, The mandatory supply institution, The induced supply institution

The rural public goods have a pivotal role in the new countryside construction. Whether the new rural construction succeeds or not, depends largely on the satisfaction coefficient to the rural public goods. Also, the tension of happiness coefficient can not be ignored. It is worthy to pay attention to establish a highly efficient, standardized system for the supply of rural public goods, especially the rational choice in the supply of entropy pool supply mode.

\section{Classification and characteristics of rural public goods}

In accordance with the degree differences of the non-competitive and non-exclusive of public goods, rural public goods can be divided into pure public goods and quasi-public goods. Pure public goods show a completely non-competitive and non-exclusive in the consumption and benefit. Quasi-public goods, also known as hybrid products, having both public goods characteristics and private goods characteristics, can not have non-competitive and non-exclusive in the same time or completely in the consumption and benefit. In general, the supply subject of rural public goods can be government, and it also can be private or market. It has "public" nature in the supply, but has a "private" nature in the consumption, which needs to pay to access, such as rural public health, rural public health care, rural social security, rural compulsory education, rural education establishments, etc.

Besides the general attributes of public goods, rural public goods also have their peculiarities, mainly for the co-existence of highly running costs and low utilization efficiency. The external diseconomies of public goods make the supply of rural public goods be limited, especially that the local government's economic capacity of providing rural public goods, due to financial constraints, is considerably limited. It is difficult to invest in the construction of rural public goods which can be a true reflection of the farmers' effective demand. And because that China's property rights reform of public goods is not in place and the boundary of the relationship between property rights and benefits is indistinct, the enthusiasm and initiative of private investment in rural public goods are seriously undermined.

According to public choice theory, people have a strong free-riding tendency in the supply of public goods. Gelding study showed that in the consumption of public goods, there exists "equal access" and "selective access". For the public goods of "selective access", it can be supplied by individual (Gelding, 1979). In the paper "the 
private production of public goods", Demsetz further pointed out that, the private sector can effectively provide public goods in condition of eliminating non-payment of fees. That is, if there is an exclusive technology, private citizens can do a good supply of certain public goods (Demsetz, 1970). Therefore, among rural public goods, with regard to public goods which do not have strong external nature and have low-cost of access, the government can play a role of guiding subject in accordance with market principles. At the same time, private and business cooperated with government should continue to strengthen the supply force of rural public goods.

\section{The formation of entropy theory and its extension in the social system}

Entropy (S) is a thermodynamic concept. Clausius made the following explanation for entropy first in 1865: "entropy is a function on the system state". In 1887, Boltzmann introduced Boltzmann factor (k), and further gave the micro-definition of entropy-type: $\mathrm{S}=\mathrm{k} \operatorname{In} \Omega$ (S indicates the macro-entropy of the system, and $\Omega$ indicates the system's disorder degrees). Its meaning is that "entropy is proportional to the number of the system micro-states' logarithm". Boltzmann's definition of the statistical interpretation of entropy makes people gain a deeper understanding of the entropy's right concept. That is "entropy is a measure of system disorder". There is a corresponding relationship between the extent of system disorder and the number of micro-states. If its micro-state number and the disorder degree is small, entropy is also small; if the micro-state number and the disorder degree is large, the entropy is great. With the generalization of the concept of entropy, some scholars have also proposed a number of concepts and terms associated with entropy, such as the letter of entropy, entropy of materials, structural entropy, evolutionary entropy, genetic entropy, environmental entropy, entropy of the system, etc. Therefore, the broad sense of entropy can also be extended to "the amount of the reduction of effective function or the increase of invalid function".

Using the entropy ideas to study the social institution system, we have the concept of social institution entropy. The so-called social institution entropy, refers to the function failure demonstrated in organization, institution, policy, energy, space and other aspects of the social institution system, and the overall effect such as the resulting the disorder (conflict, confusion and confrontation) of social institution. The various social institutions, which is the most direct reflection of the social order, constitute the norms of social behavior and order system. Effectiveness of the institution has a clear regressive effect in the process of social evolution. A management institution can play a very good guide and regulate role in the beginning of its establishment, but with the migration of time and environment (such as changes in productivity and social class), its rational and scientific level would be weakened gradually, and eventually become a factor restricted the coordinated development of society, resulting in the increase of institution entropy.

\section{The analysis and selection of rural public goods' supply mode to which entropy theory is introduce}

\subsection{An overview of the way of rural public goods supply}

The approach of rural public goods supply institution is a total of supply institution's form, speed, breakthrough, time paths, etc, taken by the main stakeholders to achieve a certain goal. Supply mode choice is primarily subject to the power structure among the various interest groups and social preference structure. Supply institution approach can be broadly classified into two types: demand-induced type and supply-led type. The two quite well-known models of the supply institution is the induced supply institution model and the mandatory supply institution model.

The induced supply institution means the purposive supply institution carried out by a group of people when there are profit opportunities in an imbalanced corresponding institution. The occurrence of the induced supply institution must have some profit opportunities originating from the imbalanced institution.

Mandatory supply institution means the supply institution caused by government decree. Different from the induced supply institution, Government is the main body of compulsory supply institution. Government's basic function is to provide order of law and security, and protect property rights in exchange for tax revenue. As a monopoly, Government can provide wide institutional services at a much lower cost than competitive organizations. Barring the advantage of scale economies in the supply institution, Government also has advantages in aspects of institution's implementation and its organized cost. For example, government can reduce the cost of benefits lost, the cost of disorder, and the cost of establishment with mandatory during the rural public goods supply.

\subsection{The compare of supply institution methods based on entropy theory}

Evaluation of the merits of the supply institution is mainly to see whether such a supply institution makes the dynamic process of economic system development to be an evolutionary process from order to disorder and then to order, and from the lower order to higher order; it is also to see whether this supply institution can break 
through the structure of the original paradigm at a lower institution costs, continuously exchange material, energy and information with the outside world, introduce into the negative entropy flow, and make use of an efficient non-linear mechanism, thereby make the supply institution to form a self-organizing system similar to "dissipative structure", and complete the concord and evolution of the supply structure.

We see the supply of rural public goods as a system, in which the induced supply institution plays the self-organizing functions. Only in self-organizing system, can the various potential resources of social elements be in a positive and driving state, and give full play to their maximum energy and creativity. Through the element integration, we can achieve the state of least system power consumption and highest performance, enhance the self-healing and self-improvement features of rural public goods supply system, and improve the ability to adapt to the social environment. As Haken said, in the role of self-organization, we can make an overall change by controlling parameters, and make the system to have a qualitative change (Haken, 1998).

In accordance with the theory of dissipative structure, open is the premise of orderly system, and the first condition for the dissipative structure's forming, maintenance and development. By opening the environment of the system, the negative entropy flow can be introduced from the outside world, so as to offset the internal entropy increase, allowing the system to complete the changes from the lower order to higher order. Environment input a variety of materials, energy and information to the system. Some are beneficial for system's operation, so system can reduce its entropy value by the interaction between the system and its internal elements after input, thereby enhancing the system's orderliness; while others will increase the system's entropy value, which is not conducive to the orderly operation of the system (North, 1990). The former can reduce the system's entropy value, so it is called negative entropy. If the external environment imports larger and stronger negative entropy flow to the system, a well-structured system will be fast and orderly development. The external environment of system mainly refers to the laws, regulations and policies. As external environment of the social system, mandatory supply institution is imported to the social system by the manner of positive or negative entropy flow, and control the direction of the supply institution.

According to the above analysis, the two supply manners, the induced supply institution and the mandatory supply institution, are not antagonistic, but complementary. There are two meanings: the one is when the induced supply institution can not meet the community's demand for rural public goods, that is when the induced supply institution leads to the intensification of entropy increase, the mandatory supply institution carried by government would compensate for deficiencies of rural public goods supply; the other is that the supply institution of some rural public goods and its changes can only be implemented by government, such as laws, orders and so on. Even if these supply institution have a huge external profits, other spontaneous private groups or social institutions are still balk at the idea. While because of the scope of application is specific, the supply of other rural public goods can only be completed by the relevant group (or groups). This category of reciprocal complement is not determined by the principle of entropy, but by the differentiation of rural public goods.

There are much in common between the induced supply institution and the mandatory supply institution. For example, they are both the product of reconciling the supply of rural public goods, whose aim is to introduce negative entropy flow, and reduce the speed of system entropy increase, and they had to obey the basic principle of cost-profit comparisons. However, there are also many differences between them, such as the difference of supply subject: the main body of the induced supply institution is the individual and a group of people, or a group; while the main body of the mandatory supply institution is the state or government. The formation of the main induced supply institution collection is mainly based on common social welfare and economic principles, and the causality of the main body of government's supply institution is much more complex than the competitive organizations (or groups). The advantages of the two supply institution are also different: the induced supply institution is mainly based on the principle of consistent consent and economic, while the superiority of the mandatory supply institution is that it can advance the supply institution at the shortest time and the fastest speed, and it can reduce the cost of the supply institution by the superiority of its own coercive force.

\section{The application of the two institution patterns in the supply of public goods in rural areas}

The subject of the supply of rural public goods should be the government, whose responsibility can not be shirked, but government is not the only supply subject (Wang, 2002). In the condition of the current limited financial resources, it is impossible for government to provide adequate public goods to meet the needs of rural development in a short time. Therefore, it must be under the condition of explicit property rights, from the perspective of the introduction of private investment, through optimizing the property of the diversification investment subject, and mobilize the social resources to supply the rural public goods. From public choice theory, 
public economics is not necessarily an exclusive economy of government monopoly, and it can be a mixed economy.

In the supply of rural public goods of China, it is neither an entirely pure induced supply institution, nor an entirely a product of mandatory supply, but a result of combination of the induced supply institution and the mandatory supply institutions (Yang, 2006). We should give full play of initiative supply and grass-roots' spontaneity and creativity, at the same time, adhere to the top-down leadership, organization and coordination of the central government. Because the mere localized supply, if lack of the top-down leadership, organization and coordination, is only the subsystem's entropy reduction, even if it can achieve great success. Due to not take integrity into account, the entropy of the entire supply system will increase sharply. It not only would undermine the existing order of the supply of rural public goods, causing social chaos and out of control, having a great blindness and destructive, but the spontaneous induced supply institution will also easily lead to the over-expansion of individual regions and individual corporate interests, whose interests would be above the social interests as a result.

Therefore, the combination of the mandatory supply institution and the induced supply institution, not only effectively promote China's effective supply of rural public goods, but this combination also have its inherent necessity. It is because the transformation from a planned economy to a market economy is an extremely complex process of the supply institution. It is not the local change of some individual arrangements in the original institution structure, but an overhaul of the whole institution structure. In such a huge and profound institutional change process, relying solely on the induced supply institution can not meet the public goods demand for the rural areas. What particularly important is that, in such a society of China, an efficient ownership structure has not been formed, and the market development is not imperfect yet, the supply institution cost of individuals and groups is so large that it would kill all the spontaneous impulse. Therefore, when the induced supply institution can not meet the rural demand for public goods, the mandatory supply institution carried out by government organically and in step, not only can make up for deficiencies in the supply institution, and reduce the organization cost and implementation cost of the supply institution, but also can be a backing of its coercive power to prevent irregular behavior occurring by institution in the new institution arrangement of market economy combining with generally adopted in rural areas, and gradually implement the government's changes from economic management institution to administrative management institution and then to political management institution, so as to get a huge advance on China's new era of socialist new countryside construction and building a socialist harmonious society.

\section{References}

Haken. (1998). Synergetic, economic entropy, the economic crisis. Shanghai, Shanghai popular science press, 187-188.

North. (1990). Institutions, Institutional Chang, and Economic Performance. Cambridge University Press.

Wang, Heng-jun. (2002). The economic crisis - economy - economic entropy. Quantitative \& Technical Economics Research, (2):15-17.

Yang, Rui-mei. (2006). Thought of China's Rural Public Goods. Nanjing Institute of Public Administration, (4):67-70. 